\title{
Generation and characterization of a Tet-On (rtTA-M2) transgenic rat
}

\author{
Yi Sheng ${ }^{1,2}$, Chih-Cheng Lin², Junming Yue ${ }^{1,2,3}$, Meena Sukhwani ${ }^{2}$, Jennifer J Shuttleworth², Tianjiao Chu ${ }^{1,2}$, \\ Kyle E Orwig ${ }^{1,2^{*}}$
}

\begin{abstract}
Background: The tetracycline-inducible gene regulation system is a powerful tool that allows temporal and dosedependent regulation of target transgene expression in vitro and in vivo. Several tetracycline-inducible transgenic mouse models have been described with ubiquitous or tissue-specific expression of tetracycline-transactivator (tTA), reverse tetracycline-transactivator (rtTA) or Tet repressor (TetR). Here we describe a Tet-On transgenic rat that ubiquitously expresses rtTA-M2 driven by the murine ROSA 26 promoter.

Results: The homozygous rat line (ROSA-rtTA-M2) generated by lentiviral vector injection, has a single integration site and was derived from the offspring of a genetic mosaic founder with multiple transgene integrations. The rtTA-M2 transgene integrated into an intron of a putative gene on chromosome 2 and does not appear to affect the tissue-specificity or expression of that gene. Fibroblasts from the ROSA-rtTA-M2 rats were transduced with a $\mathrm{TetO}_{7} / \mathrm{CMV}$-EGFP lentivirus and exhibited doxycycline dose-dependent expression of the EGFP reporter transgene, in vitro. In addition, doxycycline-inducible EGFP expression was observed, in vivo, when the $\mathrm{TetO}_{7} / \mathrm{CMV}$-EGFP lentivirus was injected into testis, kidney and muscle tissues of ROSA-rtTA-M2 rats.
\end{abstract}

Conclusions: This conditional expression rat model may have application for transgenic overexpression or knockdown studies of gene function in development, disease and gene therapy.

\section{Background}

Rats are widely used models of basic biology, human physiology and disease, but the study of genes and their functions in rats lags far behind progress in mice. During the 1980s, mice became the predominant model for functional genetic studies because progress culturing and manipulating eggs and embryos [1] of this species facilitated pronuclear injection and blastocyst injection, ex vivo [2-8]. In addition, development of germline competent embryonic stem cells $[9,10]$ enabled complex and targeted genetic manipulations (e.g., knockin and knockout). In contrast, pronuclear injection is generally considered less efficient in rats [11], germline competent ES cells were only recently established for this species $[12,13]$ and there are no reports of gene targeting in ES cells to produce knockout rats.

Rats are particularly amenable to laboratory investigations because of their intermediate size, short gestation

\footnotetext{
* Correspondence: orwigke@upmc.edu

'Department of Obstetrics, Gynecology and Reproductive Sciences, University of Pittsburgh School of Medicine, Pittsburgh, PA 15213, USA
}

and high fecundity. Rats are about ten times larger than mice and thus, provide more tissue and are more amenable to surgical manipulation, vascular access and repeated sampling. Due in part to these features, the rat is a valuable model for transplantation, cardiovascular, hypertension, neuroscience, pharmacology, diabetes, obesity, aging and cancer $[14,15]$. Furthermore, there is over a century of phenotypic and physiological data on anatomy, physiology and disease for various inbred rat models $[15,16]$. Combining these data with improved genetic and genomic resources will provide unprecedented opportunities for functional genetic studies in this species. Recognizing this opportunity, NIH has funded the Rat Expressed Sequence Tag (EST) Program, the Rat Genome Program and the Rat Genome Database and established the Rat Resource Research Center (RRRC; http://www.nrrrc.missouri.edu) during the past decade [17]. This NIH effort is matched by the National Bio Resource Project for the Rat (NBRP-Rat; http://www.anim.med.kyoto-u.ac.jp/ $\mathrm{NBR} /$ ) in Japan and rat resource repositories in Europe 
(http://www.mh-hannover.de/2652.html and http://www. euratools.eu). Thus, there is a strong impetus to expand the transgenic tools for this species.

Production of transgenic rats by pronuclear injection $[18,19]$ is now routine, albeit less efficient than for the most efficient mouse strains [14]. In addition, lentiviruses [20,21], sperm [22] and spermatogonial stem cells $[23,24]$ have recently been exploited as vehicles for modifying the rat germline and producing transgenic rats with efficiencies ranging from 6-46\%. Although germline competent ES cells have not yet been used to produce knockout rats, transgenic expression of short hairpin RNAs (shRNA) or microRNAs (miRNA) allow knockdown of target gene expression for investigations of gene function $[25,26]$. Chemical mutagenesis of germ cells by N-ethyl-n-nitrosourea (ENU) can introduce random point mutations in rat genome, but the requirement of labor-intensive screening analysis and high cost limits its application [27,28]. Finally, pronuclear injection of zinc-finger nucleases is a new tool to generate knockout rats [29]. Thus, several approaches are now available to modify and manipulate the rat genome/transcriptome and expand the transgenic resources for this species.

Some transgenic manipulations have developmental effects (e.g., embryonic lethality), which preclude studies in adult tissues. These problems can be circumvented through the use of tissue-specific and/or conditional promoters. Several inducible promoter systems have been described, including those regulated by tetracycline [30], ecdysone [31], rapamycin [32], or steroids [33]. The tetracycline (Tet)-inducible system has been the most extensively characterized and allows conditional regulation of gene expression in vitro [30] and in vivo $[34,35]$. Tet-repressor (TetR), Tet transactivator (tTA) and reverse Tet transactivator (rtTA) systems mediate tetracycline (or doxycycline)-controlled transactivation of a second recombinant transgene located downstream of composite promoters that contain tet operator (TetO) sequences (e.g., $\mathrm{TetO}_{7} / \mathrm{CMV}$ ). To date, over 100 different tetracycline-regulated transgenic mouse lines have been described (reviewed at the Tetmouse Base, http://www.zmg.uni-mainz.de/tetmouse/index.htm). In contrast, only a few rat lines have been generated, expressing either tTA [36-38] or rtTA [39]. To facilitate loss-of-function studies, two conditional (inducible) transgenic rats have been described in which TetR/TetO system is employed to regulate expression of an shRNA $[40,41]$.

Here we describe the generation and characterization of a novel Tet-On transgenic rat. This transgenic line was generated by injecting lentiviral vectors containing the ubiquitous ROSA26 promoter [42] and an rtTA-M2 transgene under the zona pellucida of one-cell rat embryos, as previously described [20]. rtTA-M2 is a mutant of rtTA that has increased stability, reduced background expression in the absence of doxycycline (Dox, tetracycline analog) and improved inducibility in the presence of Dox [43]. ROSA-rtTA-M2 rats generated in this study exhibit wide-spread expression of rtTA-M2 and Dox-regulated transactivation of a target $\mathrm{TetO}_{7} / \mathrm{CMV}$-EGFP transgene. The $\mathrm{TetO}_{7} / \mathrm{CMV}$ composite response element is commonly referred to as pTet or TRE.

\section{Results}

The ROSA26-rtTA-M2 lentiviral vector (Figure 1A) was injected under the zona pellucida of 219 1-cell S/D rat embryos. A total of 179 injected embryos (81.7\%) cleaved to produce 2-cell embryos after overnight culture and these were transferred to the oviducts of 3 pseudopregnant S/D female rats. These transferred embryos resulted in 35 live progeny and RT-PCR results (not shown) indicated that $12(34 \%)$ of these carried the ROSA26-rtTA-M2 transgene. Four founder progeny (Tg124, Tg129, Tg135, Tg144) were maintained for further characterization. Southern blot analyses indicated that founder animals had between two (Tg135) and six (Tg129) proviral insertion sites (Figure 2A). The intensity of bands corresponding to independent insertions were varying in some cases, indicating they could be genetic mosaics.

Cultures of tail fibroblasts were established for each founder animal and were transduced with a lentivirus containing the $\mathrm{TetO}_{7} / \mathrm{CMV}$-EGFP reporter transgene (Figure 1B) in the presence of Dox. EGFP fluorescence was observed 48 hours later in fibroblasts from two founders (Tg129 and Tg144) using an epifluorescent microscope (Figure 2B). EGFP expression was not observed in the absence of Dox (not shown). The founder Tg144, with five proviral integrations and the most robust Dox-dependent EGFP expression, was selected to establish a ROSA26-rtTA-M2 transgenic rat line. This founder was bred to wild type S/D females to produce F1 transgenic progeny and segregate the independent integration sites.

All transgene insertions from founder (F0) 144 were transmitted through the germline and four different integration patterns were recovered in the F1 progeny (Figure $3 \mathrm{~A}$ ). Cultures of tail fibroblasts established for each of the $\mathrm{F} 1$ progeny were transduced with Lenti-TetO ${ }_{7} /$ CMV-EGFP and maintained in the presence or absence of Dox for 48 hours. Western blot analyses demonstrated Dox-dependent expression of the EGFP reporter gene from progeny with each integration pattern and revealed that expression level was not dependent on the number of integration sites (Figure 3B). Indeed, F1 progeny with only a single integration (integration pattern D) exhibited 


\section{A. Lenti-Rosa26-rtTA-M2}

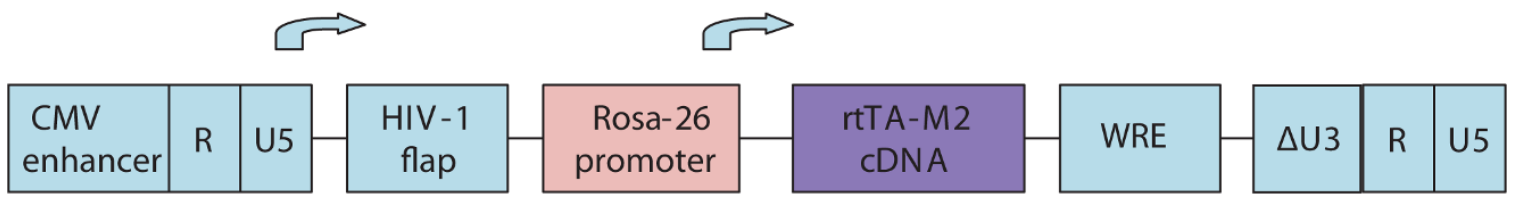

\section{B. Lenti-TetO7/CMV-EGFP}

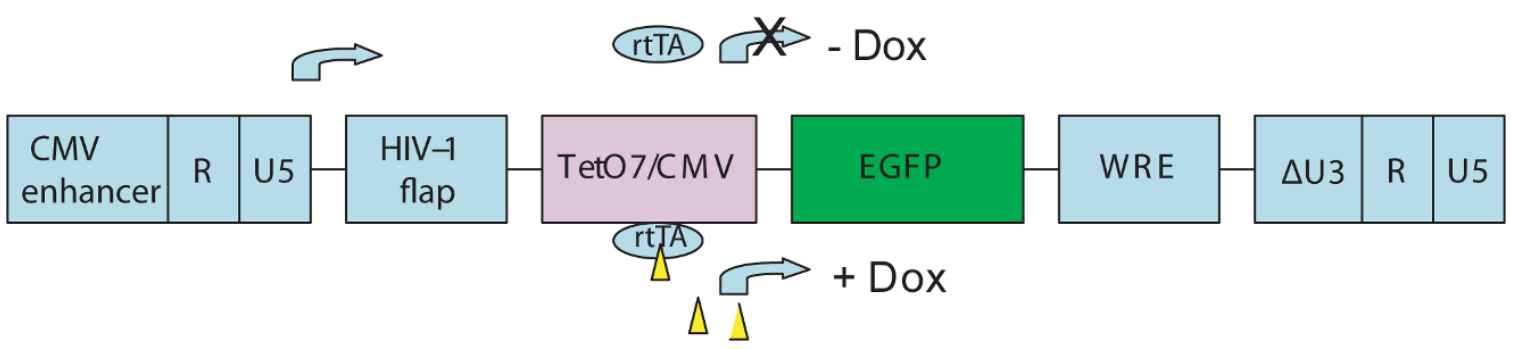

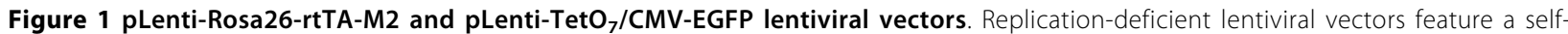
inactivating $3^{\prime} U T R$ and a CMV enhancer replaces the U3 region of the 5'UTR. WRE: woodchuck hepatitis posttranscriptional regulatory element. A. Expression of rtTA-M2 is driven by the ubiquitous Rosa-26 promoter. B. Expression of EGFP is under control of a seven repeat Tet operator and $\mathrm{CMV}$ minimal promoter (TetO 7 /CMV). In the presence of doxycycline (yellow triangles), The rtTA-M2 protein (blue ovals) encoded by the construct in $(\mathrm{A})$ binds the $\mathrm{TetO}_{7}$ operator and transactivates EGFP expression from the construct in (B).

the highest level of Dox-dependent EGFP expression (Figure 3B). F1 female 1089 and F1 male 1088 had a common single integration site corresponding to integration pattern $\mathrm{D}$ and were bred together to establish the homozygous transgenic line ROSA-rtTA-M2-1089/1088 (ROSA-rtTA-M2). Cultures of tail fibroblasts established from homozygous F2 progeny exhibited tight regulation and Dox dose-dependent induction of the $\mathrm{TetO}_{7} / \mathrm{CMV}$ EGFP reporter transgene (Figure 4A). Immunocytochemical analysis of GFP expression in cultures of tail fibroblasts from the F2-F5 generation of homozygous ROSA-rtTA-M2 rats demonstrated that the transgene is stably integrated, transmitted through the germline and not silenced (results from the F5 generation are depicted in Figure 4B-E). Rats from this line exhibited normal fertility and appeared phenotypically normal. Real-time PCR analysis was used to quantitatively evaluate rtTA-M2 expression in multiple tissues. From the twelve tissues analyzed, the highest rtTA-M2 expression was observed in skeletal muscle, followed by liver, kidney, brain, heart, adrenal, lung, intestine, testis, uterus, ovary and spleen (Figure 4F).

Linker-mediated PCR was used to amplify the junctions between chromosomal DNA and the ROSA26rtTA-M2 transgene (see Additional File 1: Figure S1 for summary of Linker-mediated PCR). Sequence comparison with the NCBI rat genomic database indicated that the transgene integrated into intron 11 of a putative gene (GeneID: 310880) on chromosome 2 (Figure 5A).
The integration site was further confirmed by PCR amplification of the junctions between genomic and transgene DNA (Figure 5B). Amplification of the 5' junction produced a $4 \mathrm{~kb}$ product (Figure $5 \mathrm{~B}$, lane 2 ), which was cleaved to the expected smaller products by EcoR1 (Figure 5B, lane 3) and Spe1 (Figure 5B, lane 4). RT-PCR was performed to compare expression of the putative gene (GeneID: 310880) in tissues of wild type and ROSA-rtTA-M2 rats. Expression of the putative gene was observed in heart, ovary and testis, but not brain, kidney or liver. There were no differences in expression of the putative gene between wild type and transgenic rats (Figure 5C).

To test the function of the rtTA-M2 transgene in vivo, the $\mathrm{TetO}_{7} / \mathrm{CMV}$-EGFP reporter lentivirus was injected into testes, skeletal muscle (hind leg) and kidney of ROSA-rtTA-M2 rats maintained with or without Dox in the drinking water. Based on real time PCR results in Figure $4 \mathrm{~F}$, these represent low (testis), medium (kidney) and high (skeletal muscle) expressing tissues. Doxdependent expression of EGFP was observed in testis (Figure 6A-D), skeletal muscle (Figure 6E-F) and Kidney (Figure 6G-H). EGFP expression was not observed for any of these tissues in the absence of Dox (Figure 6A, C, E and 6G).

\section{Discussion}

In this study, we generated a "Tet-On" transgenic rat line that exhibits ubiquitous expression of the modified 


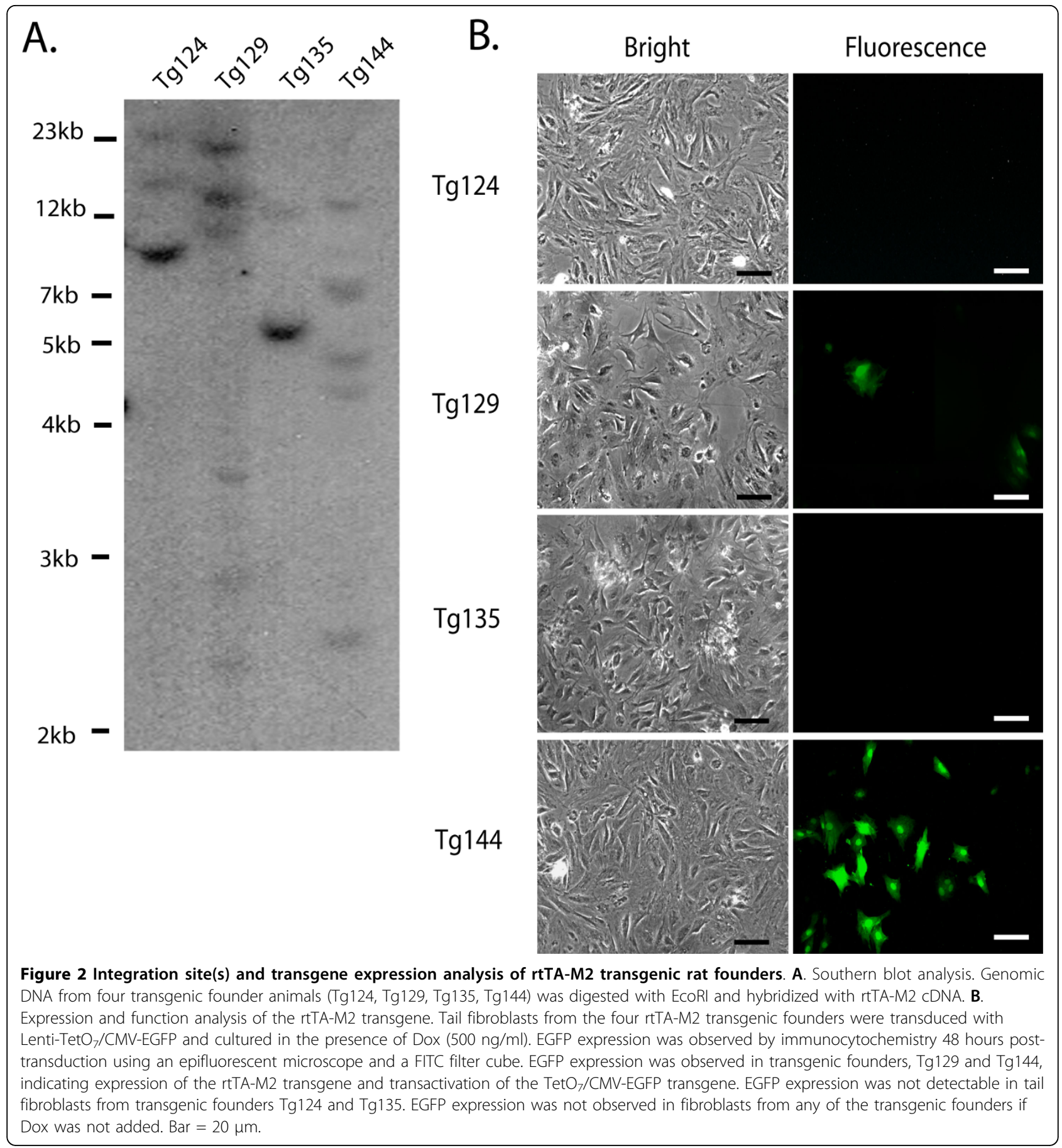

reverse tetracycline-dependent transactivator, rtTA-M2, under control of the ROSA26 promoter. As detailed in the introduction, it is the dawn of a new era for biological investigations using the rat model. Vast phenotypic and physiological data generated over the past century on rat anatomy, physiology and disease can now be combined with new genetic resources to enable state of the art functional genetic investigations. The best way to study gene function is through the generation of gainof-function (transgenic) or loss-of-function (knock-out, Knock-down) animal models. The functions of over 5,000 genes have been investigated using transgenic or knockout approaches in the mouse (Mouse Genome Database, [44]). Considerably fewer genes in the rat genome have been studied functionally using gain-of-function or loss-of-function mutants. This deficit in rats may 


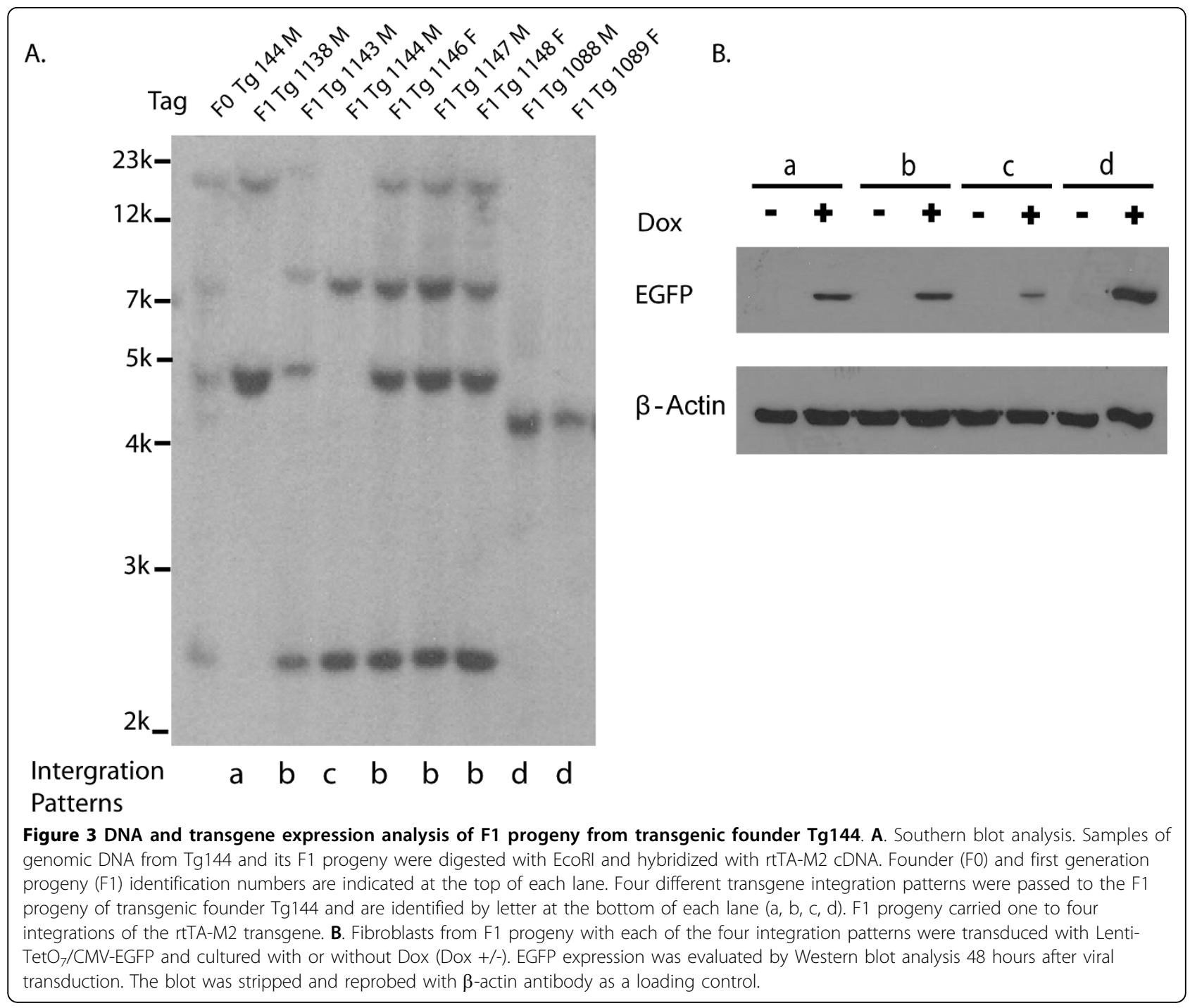

arise in part from the fact that traditional transgenic approaches in rat are less efficient than in mouse and in part from the fact that germline competent rat embryonic stem (ES) cell lines were not available, until recently $[12,13]$. To date, there are no reports that these rat ES cells have been used for targeted inactivation of specific genes and generation of knockout rats. However, Geurts and co-workers recently reported the generation of targeted mutant rats by injection of zinc finger nucleases in embryos. This may constitute a powerful approach for generating loss-of-function rat models and has the potential for widespread application if it can be combined with homologous recombination [29,45].

Several approaches have been used to generate transgenic rats, including pronuclear injection, ICSI $[22,46]$, spermatogonial stem cells $[23,24]$ and lentiviral injection into one cell embryos $[20,21]$. These approaches have varying efficiencies, strengths and weaknesses. No single approach is superior for every application. In the current study, Tet-On transgenic rats were generated by injecting lentiviral vectors (carrying the ROSA-rtTA-M2 transgene) under the zona pellucida of one cell embryos. This approach was initially described for rats by Lois and co-workers [1] and is significantly more efficient (34\% for the current study) than the standard pronuclear injection method. Lentivirus-mediated transgenesis does have limitations. The transgene cassette inserted between the viral LTRs is typically limited to less than $10 \mathrm{~Kb}$. Viral genomes with larger transgenes are not packaged efficiently, leading to decreased viral titer. The ROSA-rtTA-M2 transgene cassette was approximately $1.5 \mathrm{~Kb}$, well within the capacity of the lentiviral genome.

A second limitation of lentivirus-mediated transgenesis is that each lentiviral integration contains a single copy of the transgene, rather than head to tail arrays of multiple transgenes that can occur after pronuclear 


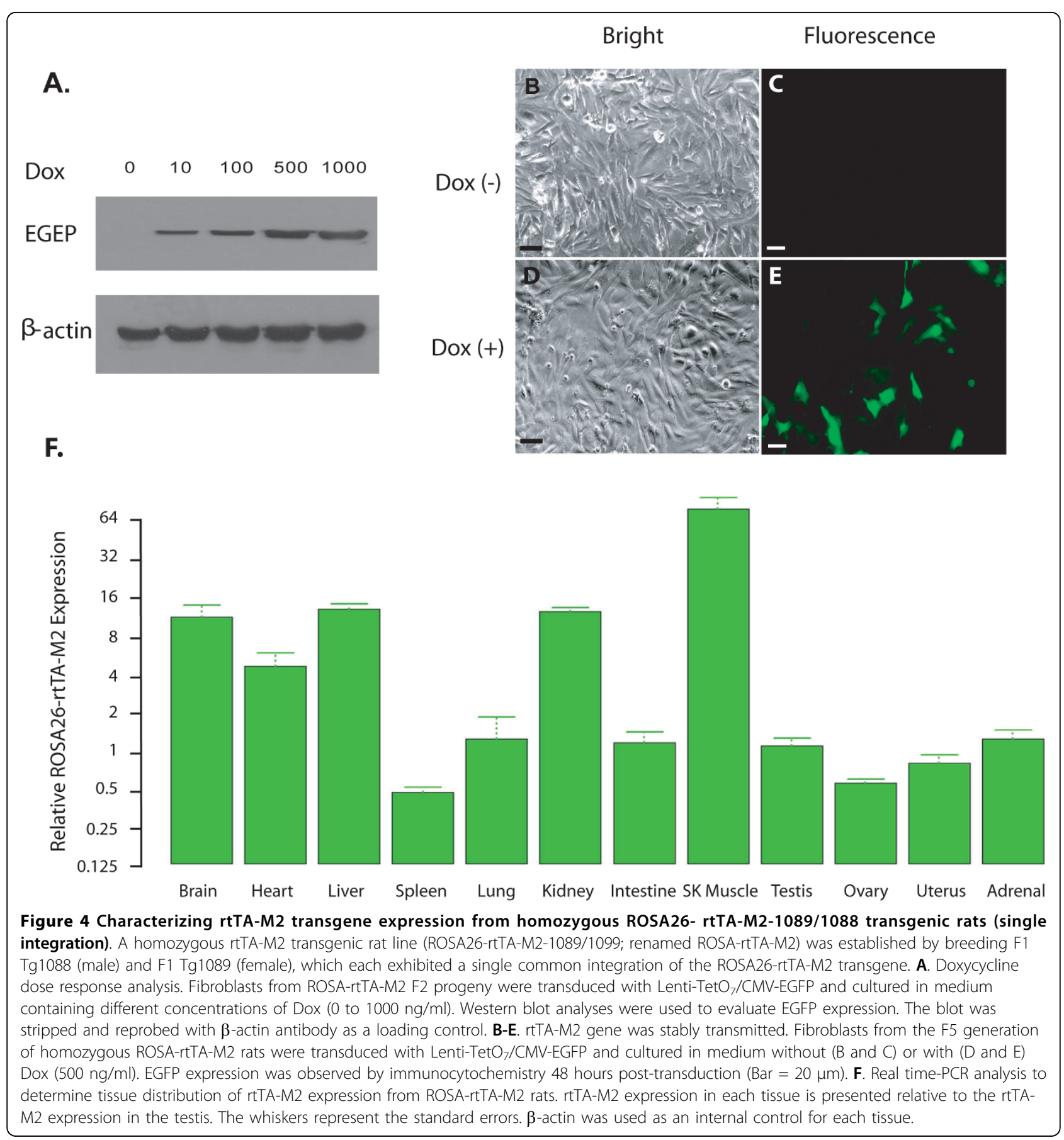

injection. This may be limiting if high levels of transgene expression are required. Also, multiple integrations in a founder generated by lentiviral injection will be segregated in the next generation. For example, founder Tg144 with five transgene integrations produced progeny with four different integration patterns (Figure 3A).

Integration site effects were also revealed in the F1 progeny from founder Tg144. F1 progeny with integration pattern d (single integration) exhibited stronger expression of the rtTA-M2 transgene than F1 progeny with integration pattern $b$ (four integrations; Figure 3B). Expression of rtTA-M2 from the single homozygous integration in the ROSA-rtTA-M2 line was sufficient to drive expression from the Lenti-TetO ${ }_{7} / \mathrm{CMV}$-EGFP reporter gene, in vitro (Figure 4A-E) and in vivo (Figure 6).

Functional genetic studies can be complicated if the genetic modification causes an embryonic lethal phenotype. This complication can be circumvented by using 


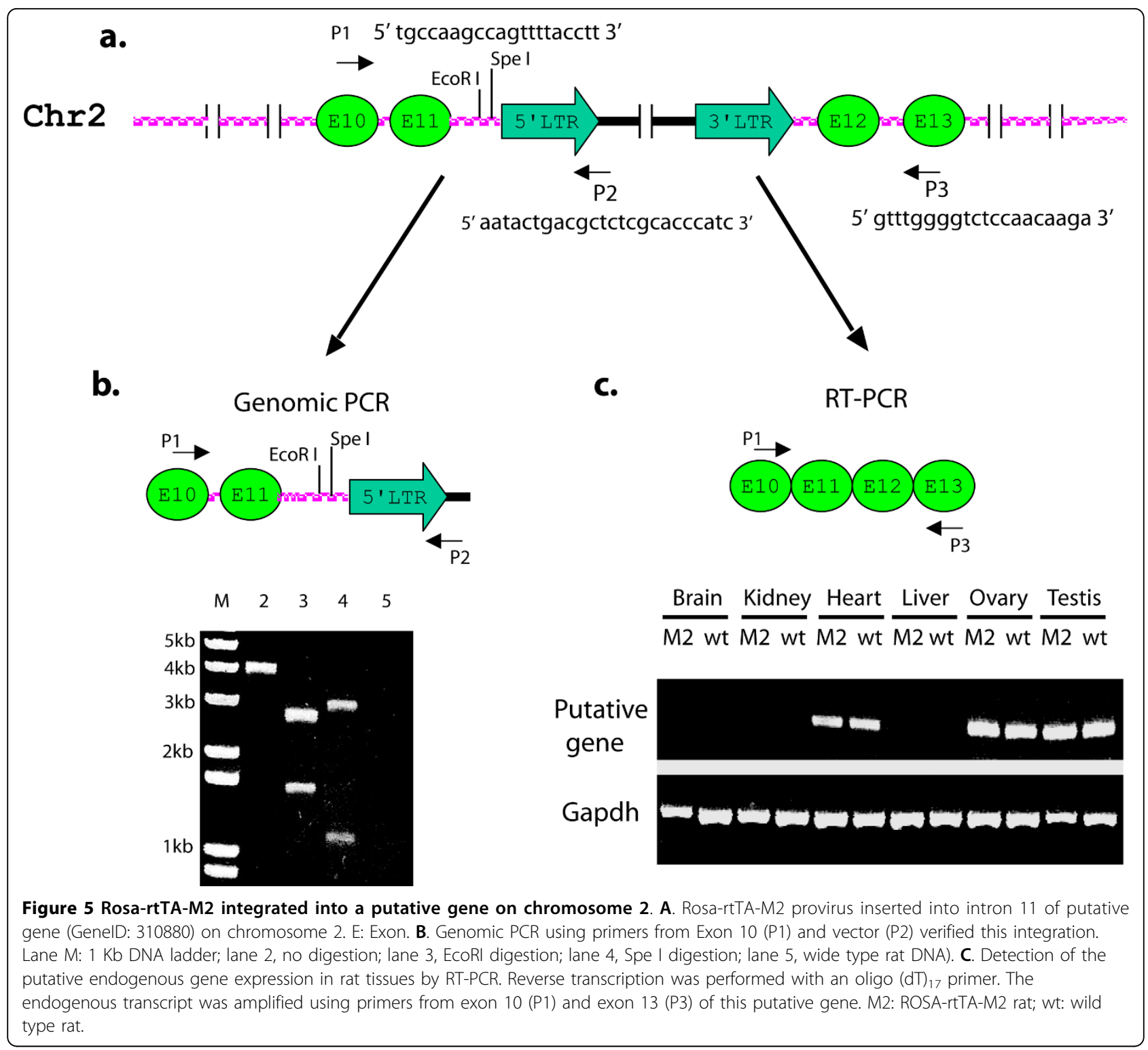

conditional expression systems that allow the target transgene to be activated at specific times of development. In the current study we utilized a mutant of the reverse Tet transactivator (rtTA-M2; [43]) that activates gene expression by binding to the Tet operator (TetO) in the presence of doxycycline (Tet-On). The M2 iteration of rtTA is stable in mammalian cells (HeLa), functions at a 10-fold lower concentration of Dox than rtTA and causes no background expression [43]. We found that rtTA-M2 exhibited similar characteristics in rat primary fibroblasts and in vivo using the ROSA-rtTA-M2 line. This transgenic rat line has been bred to homozygosity and has been propogated to the fifth generation without silencing of transgene expression. Early this year, three groups have reported generating transgenic rats by driving TetR expression with the chicken $\beta$-actin or ubiquitin promoters $[38,41]$ or tTA by the chicken $\beta$ actin promoter [40]. In addition, Konopka and coworkers [39] generated a "Tet-On" transgenic rat in which rtTA is driven by the EF1 $\alpha$ promoter. The EF1 $\alpha$ promoter is typically expected to cause ubiquitous expression, but functional rtTA expression (indicated by activation of a TetO/CMV-EGFP reporter) was limited to the testis in that study.

\section{Conclusion}

The ROSA-rtTA-M2 Tet-On rat line may provide a versatile tool for functional genetic studies because rtTA is ubiquitously expressed and can regulate conditional expression of target transgenes, in vitro or in vivo. In 


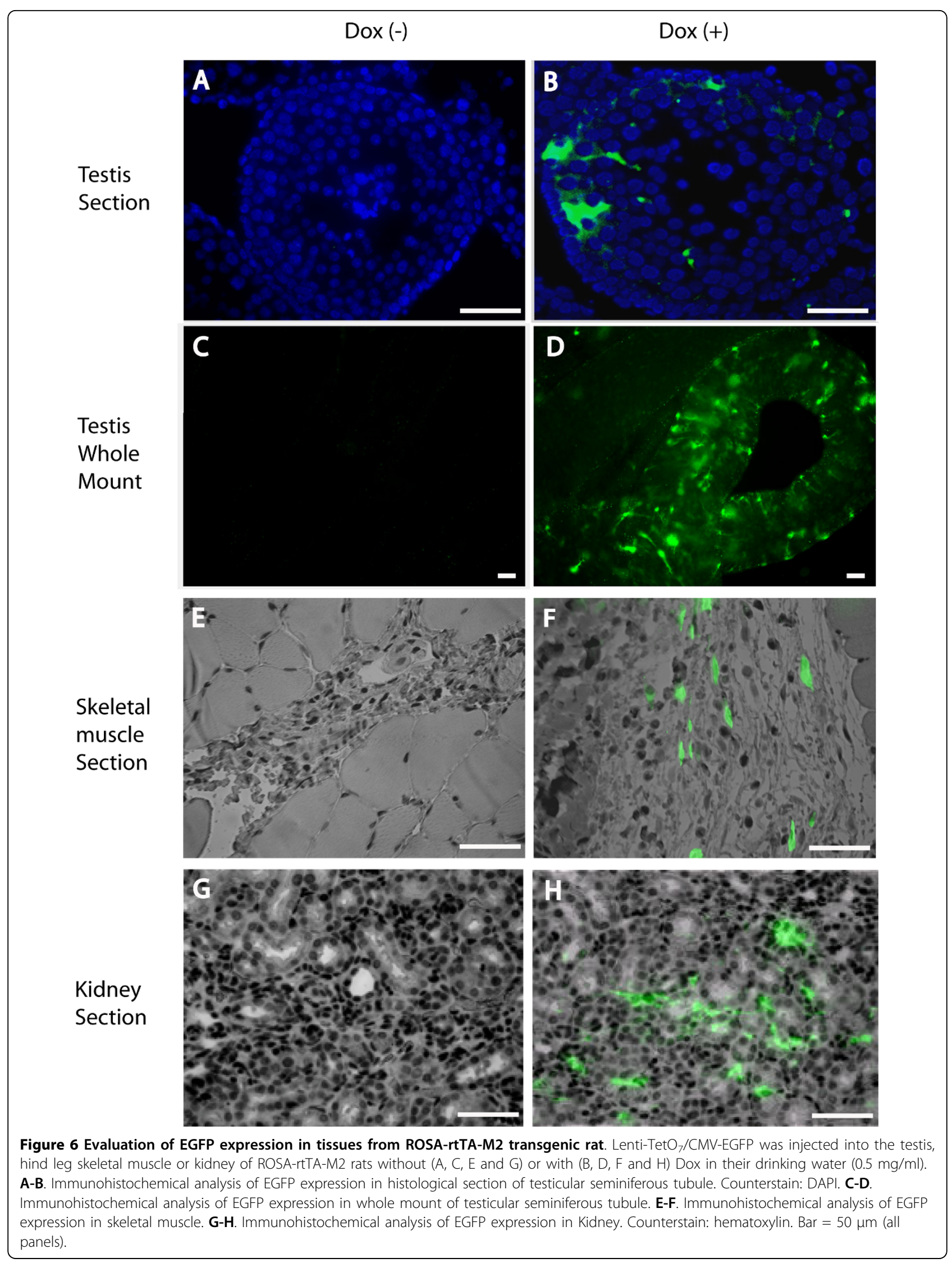


the current proof-of-principle study, an EGFP reporter gene was placed downstream of Tet operator sequences and $\mathrm{CMV}$ minimal promoter $\left(\mathrm{TetO}_{7} / \mathrm{CMV}\right)$ in a lentiviral vector. Similar constructs can be used for conditional over-expression or knock-down (using shRNA or miRNA sequences [40]) by replacing EGFP with any transgene of interest. Functions of target genes can be evaluated in vivo by injecting the target transgene into tissues of ROSA-rtTA-M2 rats as demonstrated here or by breeding ROSA-rtTA-M2 rats to a second transgenic line containing the $\mathrm{TetO}_{7} / \mathrm{CMV}$ minimal promoter and a transgene of interest. The utility and flexibility of the Tet regulatory system in rats will be increased by continuing to generate various iterations of Tet repressors, Tet transactivators and Tet responsive promoters, including the use of alternative ubiquitous or tissue-specific promoters.

\section{Methods}

Lentiviral construct and virus production

The Dox-regulated vector system consists of two lentiviral vectors, Lenti-ROSA26-rtTA-M2 and Lenti-TetO $\mathrm{O}_{7} /$ CMV-EGFP (Figure 1). Both vectors were constructed using the pC-FUW lentiviral backbone [20]. LentiROSA26-rtTA-M2 was generated by isolating the ROSA26-rtTA-M2 sequence from PBII/Rosa26/M2/ HGHpA plasmid (gift from Dr. Richard Chailet, University of Pittsburgh) and ligating this sequence into the $\mathrm{PacI} / \mathrm{EcoRI}$ sites of $\mathrm{pC}$-FUW, replacing the original UBC-EGFP sequence. Lenti-TetO ${ }_{7} / \mathrm{CMV}$-EGFP was generated by isolating the $\mathrm{TetO}_{7} / \mathrm{CMV}$ sequence from pTight-TRE (Clontech, Mountain View, CA) and inserting this sequence into $\mathrm{PacI} / \mathrm{BamH} 1$ sites of $\mathrm{pC}-\mathrm{FUW}$. The reporter EGFP gene fragment was inserted into BamH1/EcoR1 sites, which is under control of $\mathrm{TetO}_{7} /$ CMV promoter.

The VSV-G peudotyped lentiviral particles were generated by using 293FT cells and the ViraPower Lentiviral Expression System (Invitrogen, Carlsbad, California). Lentivirus supernate was collected 72 hours after transfection, passed through a $0.4 \mu \mathrm{m}$ filter unit and concentrated by ultracentrifugation at $50,000 \mathrm{~g}, 4^{\circ} \mathrm{C}$ for 2.5 hours. Pellets were resuspended in $200 \mathrm{ul}(1 / 150$ of the original volume) culture medium or PBS. Lentivirus titers were determined by p24. ELISA (Cell Biolabs, Inc, San Diego, CA).

\section{Generation of ROSA26-rtTA-M2 transgenic rats}

Female Sprague-Dawley rats (S/D, 4-5 week old) were superovulated by injection with pregnant mare serum gonadotropin (PMSG, $20 \mathrm{IU}, \mathrm{IP}$ ), followed 48 hours later by injection with human chorionic gonadotropin (hCG, 20 IU, IP). Immediately after hCG injection, superovulated females were housed with fertile S/D males overnight. Females with vaginal plugs were euthanized the next morning for collection of one-cell embryos. Lentiviral supernate $(\sim 10 \mathrm{pl})$ was injected into the perivitelline space of the one-cell embryos and the embryos were cultured overnight in KSOM medium (Minipore, Billerica, MA) supplemented with essential amino acids (Invitrogen). Embryos that developed to 2cell stage were transferred into the oviducts of peudopregnant recipient rats, as previously described [47]. All animal procedures were approved by the Institutional Animal Care and Use Committee (IACUC) of the University of Pittsburgh, which is the IACUC of record for Magee-Womens Research Institute (Assurance number A3654-01), in accordance with the National Institutes of Health Guidelines for the Care and Use of Laboratory Animals.

\section{Screening for identification of founder transgenic rats}

To identify founder (F0) transgenic rats, tail biopsies were collected at two weeks of age for genomic DNA isolation using Gentra Puregene Mouse Tail Kit (Qiagen). The resulting genomic DNA samples were screened by polymerase chain reaction (PCR) and Southern blot analysis for the rtTA-M2 transgene. The primers for PCR were: forward, 5'TTACCCGGGGAGCATGTCAAGG3' and reverse, 5'CCACCATGTCTAGACTGGACAAGAGC3'. For Southern blot analysis, 15 $\mu \mathrm{g}$ of each DNA sample was digested with EcoR1, electrophoresed on $0.8 \%$ agarose gel and transferred to a Nytran ${ }^{\circledR}$ Supercharge membrane (Whatman Inc, Sanford, $\mathrm{ME}$ ). The membranes were then hybridized overnight at $67^{\circ} \mathrm{C}$ with Rapid-hyb buffer (Amersham, Piscataway, NJ) containing labeled rtTA-M2 cDNA (RadPrime DNA Labeling System kit, Invitrogen).

A portion of each rat tail biopsy was minced and digested $\left(37^{\circ} \mathrm{C}, 15 \mathrm{~min}\right)$ in $3 \mathrm{ml}$ of $0.25 \%$ trypsin (Invitrogen) to generate a suspension of tail fibroblasts. The digestion was terminated by addition of DMEM containing 10\% FBS and the cell suspension was centrifuged (600 g, $5 \mathrm{~min}$ ). The resulting cell pellets were resuspended in $2 \mathrm{ml}$ DMEM culture medium with 10\% FBS (Hyclone, Logan, Utah). Undigested tissues were allowed to sediment to the bottom of the tube for two minutes and supernates were transferred to a 12-well plate to establish cultures of tail fibroblasts.

The fibroblasts from the rat tails which carried the rtTA-M2 transgene (determined by PCR genotyping) were passaged and transduced with Lenti-TetO ${ }_{7} / \mathrm{CMV}$ EGFP in the presence of $6 \mu \mathrm{g} / \mathrm{ml}$ polybrene (SigmaAldrich, St. Louis, MO). Following transduction, fibroblasts were maintained in medium containing doxycycline (Dox, $500 \mathrm{ng} / \mathrm{ml}$, Sigma-Aldrich). Control cultures for each founder were maintained in medium without Dox. GFP expression was evaluated 72 hours 
after transduction using an epifluorescent microscope and FITC filter cube. Founders with the highest Doxdependent GFP expression were bred with wild type S/D rats and the offspring were further evaluated by Southern blot and fibroblast culture to characterize and segregate individual transgene integrations.

\section{Determination of Lenti-ROSA26-rtTA-M2 integration site}

The integration site of the ROSA26-rtTA-M2 transgene was determined by linker-mediated (LM)-PCR $[48,49]$. Genomic DNA samples $(2 \mu \mathrm{g})$ were digested with NlaIII $(20 \mathrm{u})$ for 1 hour followed by purification using a PCR clean-up kit (Qiagen, Valencia, CA). The products were then ligated on each end with a linker containing T7 and Sp6 promoter sequences (see Additional File 1: Figure S1, step 2) followed by purification using the PCR clean-up kit (Qiagen). Primer extension was performed using the lentiviral vector specific primers, followed by two rounds of PCR using vector specific primers and primers from the linker (complementary to the T7 and Sp6 promoter sequences). The final PCR products were gel purified and subcloned into $\mathrm{PCR}^{\circ} \mathrm{II}-\mathrm{TOPO}^{\circ}$ vector (Invitrogen) for sequencing. The integration site was determined by analyzing the sequence with the NCBI Rat Genomic Sequence Blast tool (http://www.ncbi.nlm.nih.gov/genome/seq/ BlastGen/BlastGen.cgi?taxid=10116, [50]). The details of these steps and oligonucleotide sequences were shown in Additional File 1: Figure S1.

\section{Detection of rtTA-M2 expression in tissues}

Real Time-polymerase chain reaction (RT-PCR) was used to detect rtTA-M2 expression in different tissues. Total RNA from each tissue was extracted by Trizol $^{\circ}$ Reagent (Invitrogen). Reverse transcription (RT) was performed using SuperScript III reverse Transcriptase (Invitrogen) with Oligo $(\mathrm{dT})_{17}$. For SYBR Green realtime PCR, $1 \mu \mathrm{l}$ of RT product was diluted three times and used as a template in each reaction. PCR reactions were performed in triplicate for each tissue sample. Independent tissue samples were obtained from three ROSA-rtTA-M2 rats. Primers for rtTA-M2 were forward, 5'AGGCTGGACAAGAGCAAAGT and reverse, 5'ACAGGGTAGGCTGCTCAACT3'. $\beta$-actin was amplified as an internal control using the primers: forward, 5'AGGAGCGTAAAAGTTTCTCCAAG and reverse, 5'CCAGGGATAACTGCAAGGGC3'. The SYBR Greenbased real-time PCR was performed using the LightCycler 4800 real-time PCR system (Roche Applied Science; Indianapolis, IN). The PCR conditions were as follows: denature $10 \mathrm{sec}$ at $95^{\circ} \mathrm{C}$, anneal $30 \mathrm{sec}$ at $60^{\circ} \mathrm{C}$, extend $10 \mathrm{sec}$ at $72^{\circ} \mathrm{C}$, repeat 35 cycles. The relative expression of rtTA-M2 in each tissue was calculated using the
$\Delta \Delta \mathrm{Ct}$ method where the mean Ct of rtTA-M2 for each sample was divided by the mean $\mathrm{Ct}$ of $\beta$-actin for that sample. The resulting $\Delta \mathrm{Ct}$ values were used to calculate rtTA-M2 expression in each tissue relative to rtTA-M2 expressing in the testis using the formula: $2^{-\Delta C t}$ Transgenic Tissue- $\Delta \mathrm{Ct}$ Transgenic testis.

\section{Western Blot analysis}

Fibroblasts were lysed in lysis buffer $(50 \mathrm{mM}$ Tris- $\mathrm{HCl}$, $\mathrm{pH} 7.5,150 \mathrm{mM} \mathrm{NaCl}, 0.1 \%$ SDS, 1\% NP-40, 0.5\% deoxycholate), protein $(20 \mu \mathrm{g})$ from each sample was separated on a $10 \%$ denaturing polyacrylamide gel and transferred to nitrocellulose membranes (Whatman Inc.). The blots were probed with GFP antibody (Clontech), and reprobed with $\beta$-actin antibody (SigmaAldrich). GFP immunoreactivity was detected using the SuperSignal West Pico Chemiluminescent Substrate (Piece, Rockford, IL)

\section{In vivo analysis and immunohistochemistry}

The transgenic rats were anaesthetized and Lenti$\mathrm{TetO}_{7} / \mathrm{CMV}$-GFP was injected into skeletal muscle (hind legs), kidney and testis seminiferous tubules by efferent duct injection, as previously described [51]. Treated animals were given water containing $0.5 \mathrm{mg} / \mathrm{ml}$ Dox and $2.5 \%$ sucrose for 10 days (ad libetum). The control group was not treated with Dox. Following treatment, testis tissue was prepared by removing the tunica albuginea and treating briefly with collagenase IV ( $1 \mathrm{mg} / \mathrm{ml}$, Sigma) to disperse seminiferous tubules. Following treatment, GFP expression in whole mount preparations of muscle, kidney and testis tissues was observed directly, using an epifluorescent microscope and a FITC/TRITC dual emission filter cube. The dual emission filter cube is used to distinguish GFP fluorescence (green) from autofluorescence (red, [52]). Muscle, kidney and testis tissues were also fixed with $4 \%$ paraformaldehyde and prepared for immunohistochemical analysis of GFP expression in section. Tissue sections $(5 \mu \mathrm{m})$ were deparaffined, rehydrated and subjected to antigen retrieval in Sodium Citrate Buffer $(10 \mathrm{mM}$ Sodium Citrate, $0.05 \%$ Tween, pH6.0) at $97^{\circ} \mathrm{C}, 30 \mathrm{~min}-$ utes. Sections were hybridized with a mouse anti-EGFP monoclonal antibody (1:300 dilution, Clontech) for $90 \mathrm{~min}$ at room temperature. Normal mouse IgG was used in place of the anti-EGFP primary antibody for control sections. Sections were washed ( $3 \times$ ) with PBS containing 0.1\% Tween-20 (PBST), followed by incubation with an Alexa Fluor ${ }^{\circledR} 488$-conjugated goat anti-mouse secondary antibody (Invitrogen) for $60 \mathrm{~min}$. Sections were washed and mounted under glass cover slips with Vectashield mounting medium containing DAPI (Vector Laboratories Inc., Burlingame, CA) or Hematoxylin (Sigma). 
Additional file 1: Figure S1. Diagram of cloning Lenti-Rosa26-rtTAM2 integration site. Genomic DNA is partially digested with Nla III, then ligated to a linker containing T7 and Sp6 promoter sequences. Provirus integration site sequence is amplified by primer extension from vector sequence and followed by two round of PCR with vector specific, T7 and Sp6 primers. PCR products are gel purified, subcloned into $P C R^{\oplus} 2.1$ $\mathrm{TOPO}^{\oplus}$ and sequenced. A BLAST search of the rat genome was performed to identify homologous sequence.

Click here for file

[http://www.biomedcentral.com/content/supplementary/1471-213X-1017-S1.PDF]

\section{Acknowledgements}

This work was supported by the Magee-Womens Research Institute and Foundation and NIH grant RR018500 to KEO. The rtTA-M2 reverse Tet transactivator was a gift from Professor W. Hillen (University of Erlangen) acting also on behalf of Professor $\mathrm{H}$. Bujard (University of Heidelberg) and Dr. M. Gossen. The rtTA-M2 gene was subcloned to a pBluescript plasmid containing the ROSA26 promoter by Dr. J.R. Chaillet, University of Pittsburgh. The $\mathrm{pC}$-FUW lentiviral backbone was a gift from Dr. Carlos Lois, Picower Institute, Massachusetts Institute of Technology. The authors thank Tony Battelli, Julia Pascarella, Michael Bodenheimier, Karen Peters and Kate Blanner for rodent colony maintenance.

\section{Author details}

'Department of Obstetrics, Gynecology and Reproductive Sciences, University of Pittsburgh School of Medicine, Pittsburgh, PA 15213, USA. ${ }^{2}$ Magee-Womens Research Institute, Pittsburgh, PA 15213, USA. ${ }^{3}$ Current address: Department of Physiology, University of Tennessee, Memphis, TN 38163, USA

\section{Authors' contributions}

YS designed experiments, analyzed data and wrote the draft. CCL performed embryo manipulations and helped with genotyping. MS performed efferent duct injections. JY generated the lentivirus and performed real-time PCR. JJS provided animal husbandry and helped with genotyping. TJC performed statistical analysis. KEO supervised this project, helped design experiments, analyzed data and edited the final manuscript. All authors have read and approved the final manuscript.

Received: 11 January 2010

Accepted: 16 February 2010 Published: 16 February 2010

\section{References}

1. Brinster R: Cultivation of the mammalian egg. Growth, Nutrition and Metablism of Cells in Culture New York: Academic PressRothblat G, Critofalo V 1972, II:251-286.

2. Brinster RL: The effect of cells transferred into the mouse blastocyst on subsequent development. J Exp Med 1974, 140:1049-1056.

3. Gordon JW, Scangos GA, Plotkin DJ, Barbosa JA, Ruddle FH: Genetic transformation of mouse embryos by microinjection of purified DNA. Proc Natl Acad Sci USA 1980, 77:7380-7384.

4. Gordon JW, Ruddle FH: Integration and stable germ line transmission of genes injected into mouse pronuclei. Science 1981, 214:1244-1246.

5. Wagner EF, Stewart TA, Mintz B: The human beta-globin gene and a functional viral thymidine kinase gene in developing mice. Proc Natl Acad Sci USA 1981, 78:5016-5020

6. Wagner TE, Hoppe PC, Jollick JD, Scholl DR, Hodinka RL, Gault JB: Microinjection of a rabbit beta-globin gene into zygotes and its subsequent expression in adult mice and their offspring. Proc Natl Acad Sci USA 1981, 78:6376-6380.

7. Harbers K, Jahner D, Jaenisch R: Microinjection of cloned retroviral genomes into mouse zygotes: integration and expression in the animal. Nature 1981, 293:540-542.

8. Costantini F, Lacy E: Introduction of a rabbit beta-globin gene into the mouse germ line. Nature 1981, 294:92-94.

9. Evans MJ, Kaufman MH: Establishment in culture of pluripotential cells from mouse embryos. Nature 1981, 292:154-156.
10. Bradley A, Evans M, Kaufman MH, Robertson E: Formation of germ-line chimaeras from embryo-derived teratocarcinoma cell lines. Nature 1984, 309:255-256.

11. Iannaccone PGV: Production of Transgenic Rats Orlando: Academic Press, 2 2002.

12. Buehr M, Meek S, Blair K, Yang J, Ure J, Silva J, McLay R, Hall J, Ying QL, Smith A: Capture of authentic embryonic stem cells from rat blastocysts. Cell 2008, 135:1287-1298.

13. Li P, Tong C, Mehrian-Shai R, Jia L, Wu N, Yan Y, Maxson RE, Schulze EN, Song H, Hsieh CL, Pera MF, Ying QL: Germline competent embryonic stem cells derived from rat blastocysts. Cell 2008, 135:1299-1310

14. Tesson L, Cozzi J, Menoret S, Remy S, Usal C, Fraichard A, Anegon I: Transgenic modifications of the rat genome. Transgenic Res 2005, 14:531-546.

15. Jacob HJ: Functional genomics and rat models. Genome Res 1999, 9:1013-1016

16. Gill TJ, Smith GJ, Wissler RW, Kunz HW: The rat as an experimental animal. Science 1989, 245:269-276.

17. Aitman TJ, Critser JK, Cuppen E, Dominiczak A, Fernandez-Suarez XM, Flint J, Gauguier D, Geurts AM, Gould M, Harris PC, Holmdahl R, Hubner N, Izsvak Z, Jacob HJ, Kuramoto T, Kwitek AE, Marrone A, Mashimo T, Moreno C, Mullins J, Mullins L, Olsson T, Pravenec M, Riley L, Saar K, Serikawa T, Shull JD, Szpirer C, Twigger SN, Voigt B, Worley K: Progress and prospects in rat genetics: a community view. Nat Genet 2008, 40:516-522.

18. Hammer RE, Maika SD, Richardson JA, Tang JP, Taurog JD: Spontaneous inflammatory disease in transgenic rats expressing HLA-B27 and human beta $2 \mathrm{~m}$ : an animal model of HLA-B27-associated human disorders. Cell 1990, 63:1099-1112.

19. Mullins JJ, Ganten D: Transgenic animals: new approaches to hypertension research. J Hypertens Suppl 1990, 8:S35-37.

20. Lois C, Hong EJ, Pease S, Brown EJ, Baltimore D: Germline transmission and tissue-specific expression of transgenes delivered by lentiviral vectors. Science 2002, 295:868-872.

21. Brandt van den J, Wang D, Kwon SH, Heinkelein M, Reichardt HM: Lentivirally generated eGFP-transgenic rats allow efficient cell tracking in vivo. Genesis 2004, 39:94-99.

22. Kato M, Ishikawa A, Kaneko R, Yagi T, Hochi S, Hirabayashi M: Production of transgenic rats by ooplasmic injection of spermatogenic cells exposed to exogenous DNA: a preliminary study. Mol Reprod Dev 2004, 69:153-158.

23. Hamra FK, Gatlin J, Chapman KM, GrellhesI DM, Garcia JV, Hammer RE, Garbers DL: Production of transgenic rats by lentiviral transduction of male germ-line stem cells. Proc Natl Acad Sci USA 2002, 99:14931-14936.

24. Ryu BY, Orwig KE, Oatley JM, Lin CC, Chang LJ, Avarbock MR, Brinster RL: Efficient generation of transgenic rats through the male germline using lentiviral transduction and transplantation of spermatogonial stem cells. J Androl 2007, 28:353-360.

25. Dann CT, Alvarado AL, Hammer RE, Garbers DL: Heritable and stable gene knockdown in rats. Proc Natl Acad Sci USA 2006, 103:11246-11251.

26. Dann CT: New technology for an old favorite: lentiviral transgenesis and RNAi in rats. Transgenic Res 2007, 16:571-580.

27. Taurog JD, Dorris ML, Satumtira N, Tran TM, Sharma R, Dressel R, Brandt van den J, Reichardt HM: Spondylarthritis in HLA-B27/human beta2microglobulin-transgenic rats is not prevented by lack of CD8. Arthritis Rheum 2009, 60:1977-1984.

28. Olivier JD, Hart Van Der MG, Van Swelm RP, Dederen PJ, Homberg JR, Cremers T, Deen PM, Cuppen E, Cools AR, Ellenbroek BA: A study in male and female $5-\mathrm{HT}$ transporter knockout rats: an animal model for anxiety and depression disorders. Neuroscience 2008, 152:573-584.

29. Geurts AM, Cost GJ, Freyvert Y, Zeitler B, Miller JC, Choi VM, Jenkins SS, Wood A, Cui X, Meng X, Vincent A, Lam S, Michalkiewicz M, Schilling R, Foeckler J, Kalloway S, Weiler H, Menoret S, Anegon I, Davis GD, Zhang L, Rebar EJ, Gregory PD, Urnov FD, Jacob HJ, Buelow R: Knockout rats via embryo microinjection of zinc-finger nucleases. Science 2009, 325:433.

30. Gossen M, Bujard H: Tight control of gene expression in mammalian cells by tetracycline-responsive promoters. Proc Natl Acad Sci USA 1992, 89:5547-5551. 
31. No D, Yao TP, Evans RM: Ecdysone-inducible gene expression in mammalian cells and transgenic mice. Proc Natl Acad Sci USA 1996, 93:3346-3351

32. Ye X, Rivera VM, Zoltick P, Cerasoli F Jr, Schnell MA, Gao G, Hughes JV, Gilman M, Wilson JM: Regulated delivery of therapeutic proteins after in vivo somatic cell gene transfer. Science 1999, 283:88-91.

33. Burcin MM, Schiedner G, Kochanek S, Tsai SY, O'Malley BW: Adenovirusmediated regulable target gene expression in vivo. Proc Natl Acad SCi USA 1999, 96:355-360.

34. Furth PA, St Onge L, Boger H, Gruss P, Gossen M, Kistner A, Bujard H, Hennighausen L: Temporal control of gene expression in transgenic mice by a tetracycline-responsive promoter. Proc Natl Acad Sci USA 1994, 91:9302-9306.

35. Kistner A, Gossen M, Zimmermann F, Jerecic J, Ullmer C, Lubbert $H$, Bujard $\mathrm{H}$ : Doxycycline-mediated quantitative and tissue-specific control of gene expression in transgenic mice. Proc Natl Acad Sci USA 1996, 93:10933-10938.

36. Tesson L, Charreau B, Menoret S, Gilbert E, Soulillou JP, Anegon I: Endothelial expression of Fas ligand in transgenic rats under the temporal control of a tetracycline-inducible system. Transplant Proc 1999 , 31:1533-1534.

37. Braudeau C, Bouchet D, Toquet C, Tesson L, Menoret S, lyer S Laboisse C, Willis D, Jarry A, Buelow R, Anegon I, Chauveau C: Generation of heme oxygenase-1-transgenic rats. Exp Biol Med (Maywood) 2003, 228:466-471.

38. Zhou H, Huang C, Yang M, Landel CP, Xia PY, Liu YJ, Xia XG: Developing tTA transgenic rats for inducible and reversible gene expression. Int $J$ Biol Sci 2009, 5:171-181

39. Konopka W, Duniec K, Klejman A, Wawrzyniak M, Owczarek D, Gawrys L, Maleszewski M, Mallet J, Kaczmarek L: Tet system in the brain: transgenic rats and lentiviral vectors approach. Genesis 2009, 47:274-280.

40. Herold MJ, Brandt van den J, Seibler J, Reichardt HM: Inducible and reversible gene silencing by stable integration of an shRNA-encoding lentivirus in transgenic rats. Proc Natl Acad Sci USA 2008, 105:18507-18512.

41. Kotnik K, Popova E, Todiras M, Mori MA, Alenina N, Seibler J, Bader M: Inducible transgenic rat model for diabetes mellitus based on shRNAmediated gene knockdown. PLoS One 2009, 4:e5124.

42. Friedrich $G$, Soriano P: Promoter traps in embryonic stem cells: a genetic screen to identify and mutate developmental genes in mice. Genes Dev 1991, 5:1513-1523

43. Urlinger S, Baron U, Thellmann M, Hasan MT, Bujard H, Hillen W: Exploring the sequence space for tetracycline-dependent transcriptional activators: novel mutations yield expanded range and sensitivity. Proc Natl Acad Sci USA 2000, 97:7963-7968.

44. Blake JA, Bult CJ, Eppig JT, Kadin JA, Richardson JE: The Mouse Genome Database genotypes::.phenotypes. Nucleic Acids Res 2009, 37:D712-719.

45. Remy S, Tesson L, Menoret S, Usal C, Scharenberg AM, Anegon I: Zincfinger nucleases: a powerful tool for genetic engineering of animals. Transgenic Res 2009.

46. Chan AW, Luetjens CM, Dominko T, Ramalho-Santos J, Simerly CR, Hewitson L, Schatten G: Foreign DNA transmission by ICSI: injection of spermatozoa bound with exogenous DNA results in embryonic GFP expression and live rhesus monkey births. Mol Hum Reprod 2000, 6:26-33

47. Nagy A, Gertsenstein M, Vintersten K, Behringer R: Surgical Procedures in Manipulating the mouse embryo a Laboratory manual. Manipulating the mouse embryo a Laboratory manual New York: Cold Spring Harber Laboratory PressInglis J, Cuddihy J , 3 2003, 263-265.

48. Michalkiewicz M, Michalkiewicz T, Geurts AM, Roman RJ, Slocum GR, Singer O, Weihrauch D, Greene AS, Kaldunski M, Verma IM, Jacob HJ, Cowley AW Jr: Efficient transgenic rat production by a lentiviral vector. Am J Physiol Heart Circ Physiol 2007, 293:H881-894.

49. Bryda EC, Pearson M, Agca Y, Bauer BA: Method for detection and identification of multiple chromosomal integration sites in transgenic animals created with lentivirus. Biotechniques 2006 41:715-719.

50. Zhang Z, Schwartz S, Wagner L, Miller W: A greedy algorithm for aligning DNA sequences. I Comput Biol 2000, 7·203-214.

51. Ogawa T, Arechaga JM, Avarbock MR, Brinster RL: Transplantation of testis germinal cells into mouse seminiferous tubules. Int J Dev Biol 1997, 41:111-122.
52. Hermann BP, Sukhwani M, Lin CC, Sheng Y, Tomko J, Rodriguez M, Shuttleworth JJ, McFarland D, Hobbs RM, Pandolfi PP, Schatten GP, Orwig KE: Characterization, cryopreservation, and ablation of spermatogonial stem cells in adult rhesus macaques. Stem Cells 2007 25:2330-2338.

doi:10.1186/1471-213X-10-17

Cite this article as: Sheng et al:: Generation and characterization of a Tet-On (rtTA-M2) transgenic rat. BMC Developmental Biology 2010 10:17.

\section{Submit your next manuscript to BioMed Central and take full advantage of:}

- Convenient online submission

- Thorough peer review

- No space constraints or color figure charges

- Immediate publication on acceptance

- Inclusion in PubMed, CAS, Scopus and Google Scholar

- Research which is freely available for redistribution

Submit your manuscript at www.biomedcentral.com/submit
C Biomed Central 